\title{
O DESENGAJAMENTO E O CARÁTER DETERIORADO NA MODERNIDADE RADICALIZADA: UMA REFLEXÃO TEMÁTICA EM TORNO DA SOCIOLOGIA DE RICHARD SENNETT E ZYGMUNT BAUMAN
}

\begin{abstract}
RESUMO: O presente artigo tem por objetivo estabelecer uma reflexão sobre as noções de desengajamento e de caráter pessoal deteriorado por meio dos textos do sociólogo estadunidense, Richard Sennett e do sociólogo polonês, Zygmunt Bauman. Acredito, que por meio das formulações destes dois cientistas sociais tornam-se legíveis o modo que o trabalhador/cidadão global lida com o seu mundo circundante, reconfigurado em moldes ditados pelo capitalismo de especialidade flexível. Metodologicamente analisei objetivamente de forma crítica os trabalhos A corrosão do caráter e a Modernidade liquida. Em suma, estes sendo, a meu ver, trabalhos que permitem compreender como a reconfiguração do mundo do trabalho imposta pelas novas dinâmicas do sistema capitalista gerou um duro golpe no modo como a classe trabalhadora se posiciona, não somente no mundo do trabalho, mas também, em outras dimensões do convívio social mais amplo.
\end{abstract}

Palavras-chaves: Richard Sennett; Zygmunt Bauman; caráter deteriorado; desengajamento; capitalismo flexível.

\section{STOPPING AND DETERIORITY IN RADICALIZED MODERNITY: \\ A THEMATIC REFLECTION AROUND THE SOCIOLOGY OF RICHARD SENNETT AND ZYGMUNT BAUMAN}

\begin{abstract}
The purpose of this article is to establish a reflection on the notions of disengagement and of a deteriorated personal character through the texts of the American sociologist, Richard Sennett and the Polish sociologist, Zygmunt Bauman. I believe that, through the formulations of these two social scientists, the way in which the global worker / citizen deals with his / her surrounding world, reconfigured in ways dictated by flexible specialty capitalism, becomes legible. Methodologically I critically analyzed objectively the works Corrosion of character and liquid Modernity. In short, these are, in my view, works that allow us to understand how the reconfiguration of the world of work imposed by the new dynamics of the capitalist system generated a severe blow to the way the working class positions itself, not only in the world of work, but also, in other dimensions of the wider social life.
\end{abstract}

\footnotetext{
${ }^{1}$ Doutorando em Sociologia pelo Programa de Pós-graduação em Sociologia - PPGS. Universidade Federal Fluminense - UFF. Mestre em Sociologia pela mesma instituição. Graduado em Ciências Sociais pelas Faculdades Integradas Campograndense - FIC. Desde 2015 - Professor de Sociologia da Rede Estadual de Educação do Rio de Janeiro (SEEDUC/RJ). Email: patricksds@id.uff.br
} 
Keywords: Richard Sennett; Zygmunt Bauman; deteriorated character; disengagement; flexible capitalism.

\section{INTRODUÇÃO}

A modernidade que estamos inseridos, se caracteriza pela sua radicalização em variadas dimensões. Alguns estudiosos buscaram enquadrar estas radicalizações em sintonia direta com o contexto de multiplicação de novas tecnologias. Mas, o que me importa aqui são as mudanças e/ou reconfigurações institucionais da modernidade que impuseram uma condição pouco engajada que alteraram substancialmente o caráter pessoal dos indivíduos, sob esta dimensão as transformações no mundo do trabalho apresentam importantes elementos para tornar legível este processo que se espraia do universo da organização laboral para as relações pessoais da vida cotidiana.

Para compreender a questão central deste artigo é importante concentrar a análise nas transformações institucionais do mundo do trabalho por meio da passagem do modo de produção e organização laboral do capitalismo pesado para uma forma mais flexível, isto é, um capitalismo leve. Não aferindo que somente estas dimensões foram responsáveis por essa alteração no modo em que os indivíduos se alocam no mundo, mas, sugerindo a parir das leituras de Zygmunt Bauman e Richard Sennett, uma certa centralidade do trabalho nestas mudanças no caráter individual e na postura desengajada frente as peripécias sociais que afligem diretamente todo um segmento populacional.

Neste sentido, as reflexões robustas de Bauman e Sennett são extremamente pertinentes para a compreensão deste problema que aflige milhões de pessoas em todo o globo terrestre. Assim, analisarei criticamente os trabalhos $A$ modernidade líquida e $A$ corrosão do caráter para compreender como os dois sociólogos apresentaram para os seus leitores e os demais pesquisadores e pesquisadoras as transformações pessoais induzidas pela reconfiguração institucional que trouxeram à tona o chamado: capitalismo de especialidade flexível.

Portanto, as questões deste artigo, são: quais foram as operações e/ou dinâmicas relacionais que permitiram a deterioração do caráter pessoal e, por conseguinte, a adoção de posturas pouco engajadas em relação a essas mudanças e aos problemas de natureza mais variadas da vida cotidiana? Como isso impactou e vem impactando no convívio social? Por fim, tentarei responder estas questões por meio das pesquisas e 
reflexões do sociólogo estadunidense, Richard Sennett, em A corrosão do caráter -, movimento idêntico, proponho em torno do sociólogo polonês, Zygmunt Bauman, em $A$ modernidade líquida, ressaltando que foram os trabalhos principais analisados, mas, não os únicos utilizados.

\section{O CARÁTER PESSOAL NA MODERNIDADE RADICALIZADA NA ÓPTICA DE RICHARD SENNETT E ZYGMUNT BAUMAN}

Pensar a transformação e/ou desintegração do caráter pessoal é um tanto complexo, haja vista, que podem incidir diferentes elementos, que possibilitam uma virada radical no modo que os indivíduos compreendem o mundo. No entanto, longe de buscar fazer aqui uma análise superficial de elementos individuais, ainda que, relacionais também, próprios da psicologia. Zygmunt Bauman e Richard Sennett permitem a compreensão da deterioração do caráter pessoal por meio das dinâmicas cotidianas institucionais do capitalismo de especialidade flexível operadas numa nova configuração do mundo do trabalho, nesta fase da modernidade que todos nós estamos experimentando.

Como sustentava Zygmunt Bauman (2001), a lógica operada na compreensão dos indivíduos em relação ao mundo é sempre praxeomórfica, isto é, uma construção no âmbito do convívio social fortemente determinada pelo acúmulo de experiências geradas pela equação: o como é que podem fazer e, também, a maneira como usualmente a fazem. Neste sentido, a meu ver, parecem satisfatórias as análises em torno da centralidade que o trabalho flexível tem na corrosão do caráter pessoal, para ficarmos com a terminologia de Richard Sennett.

Em A corrosão do caráter: consequências pessoais do trabalho no novo capitalismo, o sociólogo estadunidense Richard Sennett informa o leitor por meio de uma robusta reflexão e pesquisa sobre os males causados aos indivíduos inseridos diretamente nas dinâmicas flexíveis da nova organização do mundo do trabalho, no que concerne a afetação direta no caráter pessoal. Tendo como expressão maior desta deterioração do caráter pessoal elementos como a incerteza e a ansiedade, gerados pela quebra institucional da perspectiva da linearidade do tempo, comum na relação trabalhador e trabalho do capitalismo pesado. 
Portanto, essa descontinuidade, sustenta Sennett, teria causado danos substanciais na vida cotidiana dos indivíduos, como, por exemplo, a perda de controle em relação as suas próprias vidas. Pois, se antes era comum fazer planejamento pessoais em relação a outras dimensões da vida a longo prazo, isso agora, fora quebrado, sendo as perspectivas de curto prazo o novo ethos motivador dos indivíduos. Isto é, a flexibilidade tende a causar ansiedade nas pessoas, uma vez que, já não se sabe mais os riscos que podem ou não serem compensados no futuro, a falta desta perspectiva, por conseguinte, gera uma expressiva insegurança em que caminhos seguir. $\mathrm{O}$ que fora "vendido" as pessoas como possibilidades maiores de liberdade, na verdade, consolidaram novas formas de controle ilegíveis, pois ao atacar

(...) a burocracia rígida e enfatizando o risco, a flexibilidade dá às pessoas mais liberdade para moldar suas vidas. Na verdade, a nova ordem impõe novos controles, em vez de simplesmente abolir as regras do passado - mas também esses novos controles são difíceis de entender. O novo capitalismo é um sistema de poder muitas vezes ilegível. (SENNETT, 2009, p. 10)

Diametralmente oposto do que fora antes "vendido" aos inseridos nesta dinâmica, Richard Sennett aponta, que de fato, o que ocorreu com a flexibilização correspondente a esta nova fase do sistema capitalista gerou um impacto bastante confuso sobre o caráter pessoal dos trabalhadores e trabalhadoras. Pois, não só impactou sobre o mundo do trabalho, mas também impactou em relação as perspectivas futuras dos indivíduos e na maneira de se relacionar com os demais indivíduos a sua volta.

Sendo assim, o caráter pessoal se desenvolve por meio das nossas experiências emocionais cuja concentração reside nos aspectos de longo prazo. Contudo, é por meio das ideias de lealdade e compromisso mútuo, antes comuns na dinâmica relacional do trabalhador com seu trabalho, institucionalmente normatizado com o capitalismo pesado do passado. A busca de metas numa lógica de longo prazo e/ou a prática antes comum de adiar a satisfação em troca de um fim futuro, foi perdido, em meio à confusão gerada nas personalidades dos indivíduos nesta nova fase. Aí concentram-se os problemas: como manter tais posturas e aspirações numa realidade impulsionada pela flexibilidade? Como manter valores duradouros e projetar metas numa lógica econômica de curto prazo? Como projetar posicionamentos leais e mutuamente compromissados numa 
lógica institucional cujo mundo do trabalho está continuamente sendo reprojetado? Isso quando, não se desfaz completamente.

Deste modo, o autor informa com bastante coerência que tais características impuseram um duro golpe sobre as dimensões psicológicas dos trabalhadores e trabalhadoras. Ora, o capitalismo cuja dinâmica laboral moldou a sociedade numa perspectiva impaciente, em que a busca por ganhos é agora imediata, por conseguinte, impôs uma nova maneira de observação e alocação no mundo, onde, teve, no limite, o caráter pessoal afetado seriamente pelo capitalismo de especialidade flexível. Ou seja, sendo este não só um condicionante de uma maneira nova de percepção do trabalho, mas sim, de toda uma concepção de organização social mais ampla.

Com a vida emocional à deriva, todo este processo impôs ao trabalhador uma forma igualmente nova de organização do tempo. Por meio da descrição feita sobre o filho de um dos trabalhadores, entrevistado por ele há vinte e cinco anos antes, para o livro Hidden Injuries of Class. Ao reencontrar, com o jovem (agora um adulto) num aeroporto, o sociólogo, Richard Sennett apresenta como após uma longa conversa notou de maneira pontual como o capitalismo flexível, não só teria afetado sua vida emocional, mas também a própria organização do tempo, de forma bem distinta, como ocorria com o pai do rapaz a um quarto de século atrás quando fora entrevistado. Pois agora, afirma Sennett, o

(...) comportamento que traz o sucesso ou mesmo apenas a sobrevivência no trabalho, portanto, pouco dá a Rico para oferecer como modelo paterno. $\mathrm{Na}$ verdade, para esse casal moderno, o problema é exatamente o contrário: como podem eles evitar que as relações familiares sucumbam ao comportamento a curto prazo, ao espírito de reunião, e acima de tudo à fraqueza da lealdade e do compromisso mútuo que assinalam o moderno local de trabalho? Em lugar dos valores de camaleão da nova economia, a família - como Rico a vê - deve enfatizar, ao contrário, a obrigação formal, a confiança, o compromisso mútuo e o senso de objetivo. Todas essas são virtudes de longo prazo. (...) Esse conflito entre família e trabalho impõe algumas questões sobre a própria experiência adulta. Como se podem buscar objetivos de longo prazo numa sociedade de curto prazo? Como se podem manter relações sociais duráveis? Como pode um ser humano desenvolver uma narrativa de identidade e história de vida numa sociedade composta de episódios e fragmentos? As condições da economia alimentam, ao contrário, a experiência com a deriva no tempo, de lugar em lugar, de emprego e emprego. Se eu fosse explicar mais amplamente o dilema de Rico, diria que o capitalismo de curto prazo corrói o caráter dele, sobretudo aquelas qualidades de caráter que ligam os seres humanos uns aos outros, e dão a cada um deles um senso de identidade sustentável. (SENNETT, 2009, p. 27) 
Essa corrosão do caráter descrita por Richard Sennett, explicitado por meio do caso de Rico pode ser notada pela busca que Rico tem em relação a manutenção de certas relações familiares, cuja sua reprodução social é concretamente bloqueada pela contraposição com as relações estabelecidas em sua vida laboral, isso porque, como ensinar, por exemplo, aos filhos a importância de se estabelecer relações duradouras com os colegas de vizinhança, ao posso que se vive em constante mudança por conta das sucessivas demissões, que geram (no caso de Rico) não somente a mudanças de emprego, mas também de cidades?

Tal perspectiva cria uma série de ressentimentos, onde, na falta de maneira concreta de adequação em meio essas contraposições entre trabalho e vida pessoal, tende a gerar uma espécie de ressentimento com outros indivíduos. Não à toa, me parece pertinente a reflexão do conservadorismo cultural por meio desta base processual. Creio que, por não conseguir obter o controle da própria vida, por conta da forma que o mundo do trabalho organiza-a em sua fase de curto prazo, o indivíduo tende a culpabilizar outros que supostamente não tenham os esforços parecidos com os seus. Orientando, por assim dizer, uma postura acusatória em relação a outros indivíduos socialmente fragilizados, tomando exceções como regras, por exemplo, na orientação de críticas difusas em relação as pessoas dependentes de benefícios sociais garantidos pelo Estado. Em torno deste problema, Richard Sennett assim o descreve:

A conversa de Rico sobre a família também o fizera, evidentemente, pensar em seus valores éticos. (...) A intolerância de Enrico [seu pai] com os negros e estrangeiros envergonhava o filho [Rico]. Mas disse que, desde que fora trabalhar, se tornara "conservador cultural". Como a maioria de seus pares, detesta os parasitas sociais, para ele encarnados na figura da mãe que vive da previdência e gasta os cheques que recebe do governo em bebida e drogas. Também se tornou um crente de padrões de comportamento comunal fixos, draconianos, em oposição aos valores de "paternidade liberal", que apenas reproduzem aquelas reuniões que não chegam a nada no trabalho. Como exemplo desse ideal comunal, disse-me que aprova a proposta atual, em alguns círculos conservadores, de tomar as crianças dos maus pais e pô-las em orfanatos. (...) Ele sabe que seu conservadorismo é apenas isso - uma comunidade simbólica idealizada. Não tem verdadeira expectativa de trancar crianças em orfanatos. Certamente teve pouca experiência, como adulto, do conservadorismo que preserva o passado; por exemplo, outros americanos o trataram, toda vez que se mudou, como se a vida estivesse apenas começando, o passado entregue ao esquecimento. $\mathrm{O}$ conservadorismo cultural que defende forma um testamento à coerência que sente faltar em sua vida. (SENNETT, 2009, p. 28-29. Grifos meus) 
Entretanto, outra dimensão importante trazida no trabalho sociológico do intelectual estadunidense, se concentra em torno da competição e a auto culpabilização alocadas sobre o caráter pessoal por meio dessa lógica flexível. Assim sendo, antes uma posição competitiva particular as empresas em disputa, passa a ser primordialmente, um aspecto importante do ethos dos trabalhadores, espraiando-se numa espécie de auto responsabilização pelo seu fracasso no atual emprego - sendo, por assim dizer, descartado termos como: "fui demitido", por exemplo - sendo encorajado psicologicamente sua substituição, por sentenças como: "enfrentei uma crise", "tive que tomar uma decisão", "fiz minhas próprias escolhas" etc., (SENNETT, 2009) naturalizando a postura do empresário na diminuição do quadro de pessoas e diminuição de custos. Ou seja, nas palavras do autor, a "sua flexível disposição de ser responsabilizado por essa qualidade de caráter, e não por um curso de ação" (SENNETT, 2009, p. 31), assim, pode-se dizer, de fato, que a "flexibilidade forçou-o a afirmar a pura força de vontade como a essência de seu próprio caráter ético" (SENNETT, 2009, p. 31).

Essa nova fase do capitalismo permite o desenvolvimento de relações pautadas num dinamismo muito distinto, de sua fase anterior. Isto é, por meio do fluxo de curto prazo e da sua flexibilidade impondo-se as relações, pouco tende a oferecer ao desenvolvimento seja social, seja econômico, as narrativas subsequentes. No entanto, o que é assustador em todo esse processo, é que essa corrosão do caráter é fruto de uma transformação bem-sucedida da organização laboral capitalista e não pelo oposto, pois

\footnotetext{
(...) a maior parte da história humana, as pessoas têm aceito o fato de que suas vidas mudarão de repente devido a guerras, fomes ou outros desastres, e de que terão de improvisar para sobreviver. Nossos pais e avós viveram em grande ansiedade em 1940, depois de suportarem o naufrágio da Grande Depressão, e enfrentando a iminente perspectiva de uma guerra mundial. (...) o que é singular na incerteza hoje é que ela existe sem qualquer desastre histórico iminente; ao contrário, está entremeada nas práticas cotidianas de um vigoroso capitalismo. (...) a corrosão de caracteres seja uma consequência inevitável. "Não há mais longo prazo" desorienta a ação a longo prazo, afrouxa os laços de confiança e compromisso e divorcia a vontade do comportamento. (...) O comportamento flexível que lhe trouxe o sucesso está enfraquecendo seu caráter de um modo para o qual não há remédio prático. (SENNETT, 2009, p. 33)
} 
Em Modernidade Líquida, o sociólogo polonês, Zygmunt Bauman faz uma análise sociológica bastante contundente, assim como Richard Sennett em torno dos males psicológicos dos quais são arrastados os trabalhadores por meio de como vem sendo institucionalizada a rotina de trabalho em sua fase flexível. Bauman sustenta que nesta nova fase de organização laboral os trabalhadores e trabalhadoras tornaram-se as peças mais “dispensáveis, disponíveis e trocáveis do sistema econômico” (BAUMAN, 2001, p. 191).

Segundo Zygmunt Bauman (2001) os requisitos desejáveis para o indivíduo nessa configuração do mundo do trabalho seriam incompatíveis com a interação social com um corpo social mais amplo, pois tornaram-se peças mais fáceis de serem trocadas, ou seja, os trabalhadores se transformaram num grupo fragilizado, sem poder em relação as negociações com os empregadores, como fora no passado. Portanto, converteram-se em elementos residuais de fáceis descartes. Daí se desenvolve a centralidade do individualismo como elemento desse caráter pessoal dos indivíduos inseridos nesta dinâmica do trabalho, pois, por compreenderem que são peças descartáveis, a perspectiva do indivíduo é, sobretudo, em direção a garantia de sua posição, pouco, importando os demais.

Se antes o adiamento da satisfação garantia a durabilidade dos esforços no mundo do trabalho, sendo este o princípio ético balizador de uma sociedade de produtores, cujas práticas capitalistas mantinham os trabalhadores de mãos dadas com o trabalho, ambos enraizados, ainda que este nunca tenha sido um casamento com a ausência de conflitos -, na sociedade dos consumidores, a mesma durabilidade é aceita, no entanto, para assegurar o desejo. Numa sociedade de consumidos é ainda "mais efêmero e frágil que o trabalho, e, ao contrário do trabalho, não reforçado por rotinas institucionalizadas, o desejo não tem chance de sobreviver" (BAUMAN, 2001, p. 200).

Assim, o que Bauman informa de forma substancial é uma configuração relacional mais ampla, no que diz respeito, as interações sociais numa sociedade marcada pelo predomínio do consumo. Ainda que o intelectual polonês esteja tratando de distintos espaços que coexistem no mesmo mundo -, mesmo sendo espaços de ações sociais diferentes, tratam-se de espaços que convergem e mesmo com os seus distanciamentos, possuem códigos semelhantes do ponto de vista comportamental. Um mundo marcado pela vulnerabilidade social e psicológica. 
A política de precarização das condições de trabalho, conscientemente reconfiguradas sobre a égide da flexibilidade vem causando danos consistentes no caráter pessoal das pessoas no atual momento. E como isso se materializa? Zygmunt Bauman explica a materialização deste caráter pessoal em contínua deterioração, por meio, do enfraquecimento e/ou decomposição dos laços humanos em suas mais variadas dimensões da vida cotidiana. Então, os compromissos antes duráveis, tornam-se compromissos transitórios e, por conseguinte, suscetíveis a rupturas unilaterais a qualquer momento, orientada por pressões psicológicas como, por exemplo, cálculos e oportunidades. Ao invés de laços e parcerias duradouras comuns as relações estabelecidas outrora. Hoje são vistos e "tratados como coisas destinadas a serem consumidas, e não produzidas; estão sujeitas aos mesmos critérios de avaliação de todos os outros objetos de consumo" (BAUMAN, 2001, p. 205).

\section{O DESENGAJAMENTO PELO PRISMA DE RICHARD SENNETT E ZYGMUNT BAUMAN}

Tomando emprestado o termo apresentado pelo sociólogo alemão, Axel Honneth (2018) a ontogênese, que diz respeito processo de reconhecimento como antecessor do conhecimento. Sustenta o autor, que "nas relações sociais humanas, há um primado ao mesmo tempo genético e categorial do reconhecimento diante do conhecimento, de um engajamento em face da apreensão neutra de outras pessoas" (HONNETH, 2018, p. 79). Deste modo, o esquecimento e/ou a negação do reconhecimento como etapa prévia ao conhecimento, gera o processo chamado de reificação. Balizado em Lukács, o autor, nos descreve que "são as coerções anônimas do mercado capitalista sobre o comportamento que levam os sujeitos a adotar uma postura não de reconhecimento, mas meramente cognitiva em relação a seu mundo circundante" (HONNETH, 2018, p. 88).

Todavia é pertinente a abertura deste ponto do texto com uma breve exposição em relação a ontogênese e a reificação, para compreender de maneira mais segura, como o mercado capitalista flexível ao reconfigurar o mundo do trabalho, não só fragmentou o caráter pessoal da classe trabalhadora, mas também, criou as bases para uma postura de negação e/ou recusa do reconhecimento precedente. Gerando o desenvolvimento de posturas difusas no cotidiano social por parte de indivíduos já 
muito fragilizados pelas dinâmicas de precarização laboral operada pelos agentes no topo da cadeia de comando dos mercados capitalistas.

O desengajamento segundo a reflexão de Zygmunt Bauman é uma postura diante das peripécias da vida cotidiana altamente desejável pelos operadores do mercado capitalista atual. Sendo está postura, altamente desejada em prol da naturalização das distorções valorativas promovidas pelo mercado flexível, mas também, gerando ganhos políticos grandes para líderes populistas que utilizam-se deste desengajamento para fomentar a radicalização populacional, jogando, por assim dizer, uma parte da população contra outra (BAUMAN, 1999, 2000, 2001, 2013, 2015 e 2017). Ora, estas distorções favorecem o encobrimento dos reais problemas sociais, cuja principal dimensão é gerada pelo próprio mercado capitalista que, segundo Bauman, nas atuais administrações governamentais pouco podem influir sobre a atuação dos mercados flexíveis.

Para o sociólogo polonês, uma questão importante para tornar legível o desengajamento, concentra-se nas próprias dinâmicas relacionais do mercado altamente dinamizado em bases tecnológicas avançadas. Isso porque, se antes os trabalhadores e trabalhadoras ainda que com grande grau de assimetria, sabiam quem davam as ordens e quem eram os seus empregadores. No capitalismo leve, flexível - o padrão da atual elite empresarial num mundo altamente globalizado, tecnológico em que o capital já não obedece, às regras e nem os limites das fronteiras nacionais, os empregadores devem ser entendidos segundo a terminologia de Bauman, como "senhores ausentes". Ou seja, a

(...) elite global contemporânea é formada no padrão do velho estilo dos "senhores ausentes". Ela pode dominar sem se ocupar com a administração, gerenciamento, bem-estar, ou, ainda, com a missão de "levar a luz", "reformar os modos", elevar moralmente, "civilizar" e com cruzadas culturais. O engajamento ativo na vida das populações subordinadas não é mais necessário (ao contrário, é fortemente evitado como desnecessário (ao contrário, é fortemente evitado como desnecessariamente custoso e ineficaz) - e, portanto, o "maior" não só não é mais o "melhor", mas carece de significado racional. Agora é o menor, mais leve e mais portátil que significa melhoria e "progresso". Mover-se leve, e não mais aferrar-se a coisas vistas como atraentes por sua confiabilidade e solidez - isto é, por seu peso, substancialidade e capacidade de resistência - é hoje recurso de poder. (...) Fixar-se ao solo não é tão importante se o solo pode ser alcançado e abandonado à vontade, imediatamente ou em pouquíssimo tempo. Por outro lado, fixar-se muito fortemente, sobrecarregando os laços com compromissos mutuamente vinculantes, pode ser positivamente prejudicial, dadas as novas oportunidades que surgem em outros lugares. (BAUMAN, 2001, p. 22)

Programas de Pós-Graduação em Ciências Sociais e Filosofia - UNIOESTE - Rua da 
Não tendo a quem reclamar, sendo aos trabalhadores inacessíveis e muitas vezes desconhecidos os comandos que são passados, torna-se inviáveis a ação contestatória diante de tal precariedade. Portanto, o capitalismo, em sua configuração leve tornou as barreiras entre os trabalhadores e trabalhadoras e o centro dos mecanismos de comando dos mercados cada vez mais distantes, para não dizer, inacessíveis. No entanto, esse processo em que o fim, conscientemente esperado e realizado é o afrouxamento das relações sociais e a cooperação entre os setores vulneráveis das sociedades inseridas numa lógica flexível, não é operada somente pelo mercado, pelo contrário, tem sua radicalização operada também por instâncias governamentais e midiáticas, que também, ganham com essa paisagem desengajada. Não à toa, Bauman ao tratar do crescimento dos líderes populistas de direita, destaca em seu trabalho Estranhos à nossa porta, que os

\begin{abstract}
(...) governos não estão interessados em aliviar as ansiedades de seus cidadãos. Estão interessados, isto sim, em alimentar a ansiedade que nasce da incerteza quanto ao futuro e do constante e ubíquo sentimento de insegurança, desde que as raízes dessa insegurança possam ser ancoradas em lugares que forneçam amplas oportunidades fotográficas para os ministros tensionarem seus músculos, ao mesmo tempo que ocultam os governantes prostrados diante de uma tarefa que são fracos demais para levar a cabo. A "securitização" é um truque de mágica, calculado para ser exatamente isso. Ela consiste em desviar a ansiedade, de problemas que os governos são incapazes de enfrentar (ou não têm muito interesse em fazê-lo), para outros, com os quais os governantes - diariamente e em milhares de telas - aparecem lidando com energia e (por vezes) com sucesso. No primeiro tipo de problema encontram-se fatores fundamentais da condição humana, como a oferta de empregos de qualidade, a confiança e a estabilidade da condição social, a proteção efetiva contra a degradação social e a imunidade quanto à negação da dignidade - todos esses determinantes da segurança e do bemestar que os governos, os quais antes prometiam pleno emprego e uma ampla previdência social, são hoje incapazes de anunciar, que dirá fornecer. (BAUMAN, 2017, p. 33-34)
\end{abstract}

Já em relação a operação midiática que também se coloca de forma engajada neste processo, sustenta Zygmunt Bauman, em A riqueza de poucos beneficiam todos nós? Que as

(...) eclosões dispersas de ira oferecem um alívio temporário para as emoções tóxicas que em geral são domesticadas e bloqueadas, e induzem um adiamento também curto - embora somente para tornar a rendição plácida e

Programas de Pós-Graduação em Ciências Sociais e Filosofia - UNIOESTE - Rua da Faculdade 645. Toledo - PR. CEP 85.903-000 Email: revistaalamedas@gmail.com 
resignada às injustiças destacadas e odiadas da vida cotidiana um pouco mais fácil de suportar. Como advertiu Richard Rorty com discernimento há poucos anos: "Se os proletários puderem ser distraídos de sua própria desesperança por pseudo-ocorrências criadas pela mídia,... os super-ricos pouco terão a temer." (BAUMAN, 2015, p. 65. Grifos do autor)

Contudo estes argumentos são necessários para a compreensão de uma gama de operações que forjaram as bases para a materialização de posturas desengajadas por parte dos segmentos populacionais mais fragilizados na contemporaneidade, ainda, que seja legível uma primazia das ações do mercado capitalista em sua especialidade flexível, cuja a ação diretiva leva ao afrouxamento e consolidação de uma forma frágil de se relacionar socialmente. Nesta fase da modernidade, cuja liquidez é sua expressão mais suscetível, os governos (alinhados a tais perspectivas de mercado) e os grandes conglomerados midiáticos tem suas parcelas de ganhos garantidos em meio a essa reconfiguração social.

Uma vez que os laços de cooperação estão cada vez mais desintegrados, corroídos pelas dinâmicas relacionais de uma época marcada pela flexibilidade do mundo do trabalho que se espraia para outras formas de se colocar na vida cotidiana. Tomar para si, uma postura engajada em prol aos benefícios de toda uma coletividade da qual o indivíduo mesmo sendo parte integrante é coagido pelas pressões do mercado. Uma postura em prol de interesses coletivos é desencorajada por variadas instâncias de poder.

Num mundo em que o futuro é, na melhor das hipóteses, sombrio e nebuloso, porém mais provavelmente cheio de riscos e perigos, colocar-se objetivos distantes, abandonar o interesse privado para aumentar o poder do grupo e sacrificar o presente em nome de uma felicidade futura não parecem uma proposição atraente, ou mesmo razoável. (...) Como os compromissos de hoje são obstáculos para as oportunidades de amanhã, quanto mais forem leves e superficiais, menor o risco de prejuízos. (...) a política de "precarização" conduzida pelos operadores dos mercados de trabalho acaba sendo apoiada e reforçada pelas políticas de vida, sejam elas adotadas deliberadamente ou apenas por falta de alternativas. Ambas convergem para o mesmo resultado: o enfraquecimento e decomposição dos laços humanos, das comunidades e das parcerias. Compromissos do tipo "até que a morte nos separe" se transformam em contratos do tipo "enquanto durar a satisfação", temporais e transitórios por definição, por projeto e por impacto pragmático - e assim passíveis de ruptura unilateral, sempre que um dos parceiros perceba melhores oportunidades e maior valor fora da parceria do que em tentar salvá-la a qualquer - incalculável - custo. (...) Em outras palavras, laços e parcerias tendem a ser vistos e tratados como coisas destinadas a serem consumidas, e não produzidas; estão sujeitas aos mesmos critérios de 
avaliação de todos os outros objetos de consumo. (BAUMAN, 2001, p. 204205)

A individualidade se torna nesta configuração o dano colateral mais perverso, que orienta as formas de apreensão do mundo circundante nas mais variadas esferas sociais. Não é somente, no mundo do trabalho que essa postura desengajada se concretiza, pelo contrário, é perceptível na forma de se relacionar com a vizinhança, com os familiares, sendo igualmente, perceptível na postura apática diante dos problemas sociais. Frações mais fragilizadas tem se posicionado em defesa de posturas cada vez mais incompatíveis com o bem-estar do grupo ao qual se pertence - o Brasil e os Estados Unidos da América, para ficarmos com dois exemplos, servem como modelos nacionais em que o capitalismo flexível tornou desengajado amplos segmentos populacionais que tem defendido líderes populistas que concretamente tem tornado cada vez mais suas vidas difíceis.

Richard Sennett aponta a desconfiança dos indivíduos em relação aos trabalhadores que possuem estabilidade, mesmo nesta fase flexiva do capitalismo, como fator importante para a reflexão. Sennett utiliza o desdém de Rico em relação a sua carreira estável como professor universitário. Podemos, neste ponto, tomar como indicativo a própria percepção que algumas pessoas possuem no caso brasileiro em relação aos funcionários públicos. Estabilidade, é percebida por esses indivíduos modulados numa logica de trabalho flexível com certo desdém a estabilidade, pelo menos, assim o demonstram publicamente certa rejeição a estas práticas duráveis, além de verem como conformistas os trabalhadores estáveis, que não se "arriscam" como muitos trabalhadores envolvidos nesta dinâmica confusa acreditam estarem fazendo.

Em A corrosão do caráter, Richard Sennett demonstra a pertinência da flexibilização do horário de trabalho, mas também, a centralidade da automação tecnológica dos processos produtivos antes feitos por especialistas, como elementos relevantes para o desengajamento dos indivíduos em relação a preponderância do trabalho que fazem em suas vidas. Com o advento da automação em todas as fases do processo produtivo, os indivíduos ao invés de terem suas capacidades cognitivas desafiadas, muito pelo contrário, precisam saber somente pressionarem botões em painéis. Isso, para Sennett é extremamente nocivo no desenvolvimento psicológico dos indivíduos. Assim, diz o sociólogo: 
O que é realmente novo é que, na padaria, percebi um terrível paradoxo. Nesse local de trabalho high-tech, flexível, onde tudo é fácil de usar, os empregados se sentem pessoalmente degradados pela maneira como trabalham. Nesse paraíso do padeiro, tal reação ao trabalho é uma coisa que eles próprios não entendem. Operacionalmente, tudo é muito claro; emocionalmente, muito ilegível. (SENNETT, 2009, p. 79)

Diferente das velhas estruturas do capitalismo pesado, onde cada trabalhador tinha a noção do que estava fazendo, em sua fase flexível o trabalho é cada vez mais ilegível. Não, cabendo em sua organização grandes dificuldades para a realização dos processos o que gera nos trabalhadores uma repulsa cada vez maior pelo trabalho realizado, uma vez que não são desafiados em suas atividades. Isso, tende a tornar o trabalho cada vez mais distante do trabalhador, que é processualmente levado a se relacionar de maneira indiferente em relação ao trabalho.

A “dificuldade é contraprodutiva num regime flexível. Por um terrível paradoxo, quando diminuímos a dificuldade e a resistência, criamos as condições mesmas para a atividade acrítica e indiferente por parte dos usuários" (SENNETT, 2009, p. 84). Não à toa, uma das entrevistadas da padaria, ironicamente, diz ao professor norte-americano: “- Padaria, sapataria, gráfica, é só dizer, eu tenho as qualificações” (SENNETT, 2009, p. 82). Essa atividade exercida de maneira acrítica e indiferente no universo laboral, são primordiais para uma reprodução de visões acríticas em relação a outras instâncias do convívio social.

Contudo, a meu ver, a análise de Richard Sennett traz à tona um elemento fundamental para compreendermos uma postura cada vez mais desengajada por parte de variados segmentos populacionais, e não somente, os trabalhadores imbricados no seio desta grande máquina de destruição pessoal que o capitalismo flexível é o combustível e ao mesmo tempo motor -, as "novas condições de mercado obrigam grandes números de pessoas a assumir riscos, mesmo sabendo os jogadores que as possibilidades de retorno são tênues" (SENNETT, 2009, p. 104). Aqui Sennett insere no debate a ideia de "mercados em que o vencedor leva tudo" que nos permite ler o desengajamento por meio da contraposição entre o bem-estar coletivo e a meritocracia mediada pelo risco.

Essa aceitação do risco ocorre no que os economistas Robert Frank e Philip Cook chamam de "mercados em que o vencedor leva tudo". Nessa paisagem 


\begin{abstract}
competitiva, os bem-sucedidos levam a mesa toda, enquanto a massa dos perdedores fica com migalhas para dividir entre si. A flexibilidade é um elemento-chave para permitir a formação desse mercado. Sem um sistema burocrático que canalize os ganhos de riqueza através de uma hierarquia, as recompensas gravitam para os mais poderosos; numa instituição sem peias, os que estão em posição de açambarcar tudo o fazem. A flexibilidade, assim, acentua a desigualdade, pelo mercado em que o vencedor leva tudo. (...) $\mathrm{Na}$ opinião desses economistas, a "estrutura de suborno [da economia moderna] levou demasiados [indivíduos] a abandonar alternativas em busca dos prêmios máximos". (SENNETT, 2009, p. 105. Grifos do autor)
\end{abstract}

Portanto, os "mercados em que o vencedor leva tudo" incuti socialmente nas mentes dos indivíduos a concepção difusa de que "você depende de suas capacidades para vencer", esta primazia meritocrática mediada pelo risco. No fim e a cabo, leva diversos indivíduos ao fracasso, pois o vencer e perder, está para além de capacidades ideologicamente incutidas. Na verdade, tal perspectiva amplia as posturas desengajadas, na busca por sucesso e/ou ganhos imediatos. $\mathrm{Na}$ atual fase capitalista as pessoas são levadas a colocarem como alicerces de suas vidas o risco. Como diz Sennett, o "risco é um teste de caráter; o importante é fazer o esforço, arriscar a sorte, mesmo sabendo-se racionalmente que se está condenado a fracassar" (SENNETT, 2009, p. 106). Em suma, a construção sociológica de Richard Sennett e de Zygmunt Bauman tornam legíveis processos difusos, ainda que pensados e calculados de forma consciente.

\title{
CONCLUSÃO
}

Em linhas gerais, no decorrer deste artigo busquei fazer uma reflexão crítica em torno das formulações sociológicas de Richard Sennett e de Zygmunt Bauman. Tendo privilegiado, como os materiais primordiais para a construção da reflexão em torno da deterioração do caráter pessoal e do desengajamento os livros A corrosão do caráter: as consequências pessoais do trabalho no novo capitalismo e Modernidade líquida.

A legibilidade da corrosão do caráter pessoal (para ficarmos como a terminologia, de Richard Sennett) e, também, do desengajamento - primordialmente passa pela centralidade em que a organização do mundo do trabalho possuí na formação das maneiras de se colocar no mundo. Na sua fase flexiva, os processos operados conscientemente pelos controladores dos mercados institucionalizaram formas cada vez mais desinteressadas, desengajadas, deterioradas etc., não somente, manifestadas no 
mundo do trabalho. Pelo contrário, influindo sobre os laços e relações mais particulares num convívio social mais amplo. Dito de outro modo, assim como no modo de organização laboral em sua fase pesada criou maneiras de se relacionar com o mundo, em sua fase leve, não foi diferente neste aspecto. Ainda que os danos psicológicos assumam um caráter mais destrutivo para o indivíduo afetado diretamente por esse mundo do trabalho cada vez mais ilegível para os que dele participam.

Estas transformações operadas no mundo do trabalho, além de gerarem uma enorme instabilidade emocional, onde sentimentos como ansiedade, insegurança e incerteza que, por fim, afetaram frontalmente o caráter pessoal e, por conseguinte, permitiram a consolidação de posturas desengajadas. Possibilitou um estado naturalizado de agravamento das desigualdades sociais - justificado, por assim dizer, pelos eufemismos justapostos do risco e fracasso, encarados por suas vítimas diletas como categorias explicativas do real estado de coisas. Impossibilitados de conhecer os reais causadores desses mosaicos de desgraças pessoais.

Grupos midiáticos e governos populistas de direita lucram politicamente com o desfoco de uma massa global espoliada que se auto culpabiliza. Ainda na década de noventa do século XX, o sociólogo alemão, Ralf Gustav Dahrendorf dizia que o século XXI poderia ser o século do autoritarismo (GEISELBERGER, 2019), pena que o poderia já deixou de ser uma possibilidade anti-iluminista e a cada dia que passa, consolida-se como uma realidade concreta de nossa modernidade radicalizada. Contudo, assim como de forma quase profética, Dahrendorf nos legou este valioso indicativo a mais de vinte anos atrás. Richard Sennett e Zygmunt Bauman por meio de seus trabalhos robustos, linguagem atraente e acessível para os mais variados públicos, no mesmo século XX, tornaram legíveis os processos nocivos de um mercado radicalizado, leve e flexível, esguio à controles burocráticos que, em última análise, está na raiz da institucionalização dos sentimentos confusos, difusos e ambíguos que hoje materializam-se em Bolsonaro (no Brasil), Trump (nos Estados Unidos), Orbán (na Hungria), Salvini (na Itália), Jonson (no Reino Unido da Grã-Bretanha), e tantos mais.

Por tudo isso, a meu ver, os trabalhos do sociólogo estadunidense, Richard Sennett e do sociólogo polonês, Zygmunt Bauman são materiais primordiais para a compreensão das relações sociais na modernidade radicalizada que estamos inseridos. Pois, por um lado, permite a legibilidade das fraturas sociais abertas conscientemente 
pelos operadores dos mercados globais e os ganhos sociais de instâncias que não possuem forças para restaurar o enraizamento do capital novamente, então, dirigem-se o foco para outras esferas e garantem seus ganhos; por outro lado, permitem compreender também a maneira que esta nova configuração institucional do trabalho adentrou na vida das pessoas afetando seriamente suas qualidades emocionais, deteriorando o caráter pessoal e fazendo do desengajamento a forma preponderante de atuar num mundo social cada vez mais desregulamentado em toda sua dinâmica, cada vez mais tóxico para os seus indivíduos mais fragilizados.

\section{REFERÊNCIAS BIBLIOGRÁFICAS}

BAUMAN, Zygmunt. Modernidade líquida. Rio de Janeiro: Zahar, 2001.

Globalização - as consequências humanas. Rio de Janeiro: Zahar, 1999.

Em busca da política. Rio de Janeiro: Zahar, 2000.

A riqueza de poucos beneficia todos nós? Rio de Janeiro: Zahar, 2015.

2013.

Danos colaterais: desigualdades sociais numa era global. Rio de Janeiro: Zahar,

Estranhos à nossa porta. Rio de Janeiro: Zahar, 2017.

BECK, Ulrich. A metamorfose do mundo: novos conceitos para uma nova realidade. Rio de Janeiro: Zahar, 2018.

FRIDMAN, Luis Carlos. A "liquidez" contemporânea na obra de Zygmunt Bauman. TRIEB, Rio de Janeiro, v. 16, p. 29-46, 2018.

GEISELBERGER, Heinrich. Prefácio. In: APPADURAI, Arjun ... [et al.]. A grande regressão: um debate internacional sobre os novos populismos e como enfrentá-los. São Paulo: Estação liberdade, 2019.

GIDDENS, Anthony. As consequências da modernidade. São Paulo: Unesp, 1991.

HONNETH, Axel. Reificação: um estudo de teoria do conhecimento. São Paulo: Ed. Unesp, 2018.

SENNETT, Richard. A corrosão do caráter: as consequências pessoais do trabalho no novo capitalismo. 14. ed. Rio de Janeiro: Record, 2009.

A cultura do novo capitalismo. 3. ed. Rio de Janeiro: Record, 2011. 
Autoridade. 3. ed. Rio de Janeiro: Record, 2014. 